\title{
Analisis Biaya Pekerjaan Sloof Pada Proyek Pembangunan Gedung BPJN Aceh
}

\author{
M. Ricci Akbar ${ }^{1}$ Mahmuddin $^{2}$ Tripoli $^{3}$ \\ 1,2,3 Jurusan Teknik Sipil, Universitas Syiah Kuala, Banda Aceh 23111, Indonesia \\ Email: muhammadricciakbar@gmail.com
}

\begin{abstract}
Construction projects are temporary, non-repetitive, non-routine activities, have a start and end time, have limited resources, and are supportive of achieving the specified targets. Cost budgeting is the process of calculating the volume of work, the price of various materials and the work that will occur in a construction. The problem in this research is the large amount of material needed for the Phase III BPJN Building Construction Project-Banda Aceh. This research is needed to calculate the amount of material needed for the Phase III-Banda Aceh BPJN Building Project Development. Planning or calculation of material costs and the amount of material based on the 2016 Job Unit Price Analysis (AHSP). The data needed in this study is secondary data. The plan of the results of this research is the planning of material costs needed in the planning of building the BPJN Phase III-Banda Aceh building. The benefits of this research will be input into planning materials and material costs in future project development plans.
\end{abstract}

Keywords: Project, Construction, Material, BPJN Building

\begin{abstract}
Abstrak
Proyek konstruksi merupakan pekerjaan yang bersifat sementara, tidak berulang, tidak rutin dan ditentukan waktu awal dan akhir, sumber daya terbatas, dan dimaksudkan untuk mencapai sasaran yang ditetapkan. Taksiran anggaran biaya merupakan proses perhitungan volume pekerjaan, harga dari berbagai macam bahan dan pekerjaan yang akan terjadi pada suatu konstruksi. Permasalahan dalam penelitian ini adalah berapa banyak bahan atau material yang diperlukan untuk Pembangunan Proyek Gedung BPJN Tahap III-Banda Aceh. Penelitian ini bertujuan untuk menghitung jumlah material yang diperlukan untuk Pembangunan Proyek Gedung BPJN Tahap III-Banda Aceh. perencanaan atau perhitungan biaya material dan jumlah material berdasarkan Analisa Harga Satuan Pekerjaan (AHSP) 2016. Data yang diperlukan dalam penelitian ini yaitu data sekunder. Rencana hasil penelitian ini adalah perencanaan biaya material yang dibutuhkan dalam pembangunan proyek gedung BPJN Tahap III-Banda Aceh. Manfaatnya adalah sebagai masukan dalam merencanakan bahan dan biaya material dalam pembangunan proyek gedung di masa yang akan datang.
\end{abstract}

Kata Kunci: Proyek, Konstruksi, Material, Gedung BPJN.

\section{Pendahuluan}

\subsection{Latar Belakang}

Proyek merupakan pekerjaan yang bersifat sementara, tidak berulang, tidak rutin, menentukan waktu awal dan akhir, sumber daya terbatas, dan dimaksudkan untuk mencapai sasaran yang ditentukan. Sumber daya pada proyek kontruksi biasanya berupa: tenaga kerja, material, peralatan, metode dan finansial. Kemampuan kontraktor untuk menyediakan modal kerja akan sangat berpengaruh terhadap pekerjaan konstruksi. Kontraktor tidak harus menunggu turunnya modal dari owner ataupun pinjaman dari bank, sehingga dapat memenuhi target rencana penjadwalan waktu proyek konstruksi. Profit kontraktor adalah keuntungan yang diperoleh pada satu proyek yaitu selisih dari RAB (Rencana Anggaran Biaya). Keuntungan finansial yang akan diperoleh tergantung dari cara mengatur sumber daya yang ada. Semakin bagus kontraktor mengatur sumber daya yang ada semakin besar pula keuntungan yang akan didapatkan.
Taksiran anggaran biaya adalah proses perhitungan volume pekerjaan, harga dari berbagai macam bahan dan pekerjaan yang akan dilaksanakan pada suatu konstruksi. Sebagai dasar perhitungan yang digunakan dalam perencanaan anggaran biaya proyek saat ini yaitu suatu standar tata cara perhitungan harga satuan pekerjaan untuk merencanakan anggaran biaya bangunan.

\subsection{Rumusan Masalah}

Permasalahan dalam penelitian ini adalah berapa banyak bahan atau material yang diperlukan untuk Pembangunan Proyek Gedung BPJN Tahap IIIBanda Aceh.

\subsection{Tujuan Penelitian}

Tujuan penelitian adalah menghitung jumlah material yang diperlukan untuk Pembangunan Proyek Gedung BPJN Tahap III-Banda Aceh. 


\subsection{Manfaat Penelitian}

Manfaat dari penelitian ini sebagai gambaran dalam merencanakan bahan dan biaya material pada pelaksanaan pembangunan proyek gedung di waktu yang akan datang.

\subsection{Ruang Lingkup Penelitian}

Ruang lingkup penelitian adalah proses perencanaan atau perhitungan biaya material dan jumlah material berdasarkan Analisa Harga Satuan Pekerjaan (AHSP) 2016.

\subsection{Hasil Analisi}

Data sekunder diperoleh dari kontraktor di Kota Banda Aceh. Data yang diperlukan dalam penelitian ini berupa data sekunder. Metode pengolahan data menggunakan Microsoft Excel. Rencana hasil penelitian ini adalah perencanaan biaya material yang dibutuhkan dalam pembangunan proyek gedung BPJN Tahap III-Banda Aceh.

\section{Tinjauan Pustaka}

\subsection{Proyek Konstruksi}

Menurut Ervianto ${ }^{[1]}$ proyek konstruksi adalah rangkaian pekerjaan yang hanya sekali dilakukan dan berjangka waktu pendek. Dalam rangkaian pekerjaan ini, terjadi proses pengolahan sumber daya proyek menjadi hasil pekerjaan yang berupa infrastruktur. Proses yang dilakukan dalam rangkaian pekerjaan tersebut melibatkan beberapa pihak, baik secara langsung maupun tidak langsung. Hubungan antara beberapa pihak yang terlibat pada proyek dibedakan atas hubungan fungsional dan hubungan kerja. Banyak pihak yang terlibat dalam proyek konstruksi menyebabkan konflik yang sangat tinggi.

\subsubsection{Pengertian Proyek Konstruksi}

Menurut Dipohusodo ${ }^{[2]}$ proyek konstruksi adalah pekerjaan yang berkaitan dengan upaya pembangunan infrastruktur, biasanya mencakup pekerjaan inti yang masuk kedalam bidang teknik sipil dan arsitektur. Insfrastruktur tersebut meliputi aspek kepentingan masyarakat yang sangat luas berupa perumahan, apartement, perkantoran, pabrik, bangunan industri, jembatan, jalan raya termasuk jalan layang, rel kereta api, pembangkit tenaga listrik, tenaga nuklir, bendungan, terowongan, PLTA, saluran pengairan, sistem sanitasi dan drainase, bandar udara dan hanggar pesawat terbang, pelabuhan dan bangunan lepas pantai, jaringan kelistrikan dan telekomunikasi, kilang minyak dan jaringan plumbing dan lain sebagainya.

\subsubsection{Jenis-Jenis Proyek Konstruksi}

Menurut Ervianto ${ }^{[1]}$ proyek konstruksi bisa dibedakan kedalam dua jenis kelompok infrastruktur, yaitu :
1. Bangunan gedung: pabrik, kantor, rumah, dan lain-lain. Karakteristik kelompok bangunan ini adalah:

a. Proyek konstruksi berfungsi sebagai tempat tinggal atau pekerja.

b. Pekerjaan dilakukan di tempat yang relatif sempit dan pondasi biasanya sudah diketahui.

c. Manajemen dibutuhkan untuk pelaksanaan pekerjaan.

2. Bangunan sipil: bendungan, jembatan, jalan, dan infrastruktur lainnya. Ciri-ciri dari kelompok bangunan ini adalah :

a. Proyek konstruksi dikerjakan untuk kepentingan manusia.

b. Proyek dikerjakan di tempat yang luas atau lebar dengan kondisi pondasi sangat berbeda satu sama lain dalam suatu proyek.

c. Manajemen diperlukan untuk menyelesaikan permasalahan dilapangan.

\subsubsection{Kontrak Kontruksi}

Menurut Faizal ${ }^{[3]}$ kontrak adalah dokumen penting pada proyek. Perihal keterkaitan hak dan kewajiban antar pihak dengan alokasi resiko diatur didalam kontrak. Setelah proses penunjukan langsung atau tender selesai dibuatlah kontrak kerja konstruksi yang bertujuan sebagai landasan hukum dan tuntunan pelaksanaan bagi kontraktor yang diberikan oleh owner proyek, kontrak kerja juga berfungsi sebagai panduan bagi kontraktor ataupun owner proyek mengenai perihal yang menjadi kewajiban dan hak dalam suatu hubungan kerja pelaksanaan kontrak kerja konstruksi.

Bentuk kontrak Unit Price Menurut Faizal, 2016 adalah suatu kontrak yang volume pekerjaannya tertera didalam kontrak hanya menjadi perkiraan dan akan ditinjau ulang untuk menentukan volume pekerjaan yang akan dilaksanakan. Adapun beberapa jenis kontrak konstruksi, antara lain :

1. Aspek perhitungan biaya

a. Fixed Lumpsum Price :

Secara umum, kontrak Fixed Lumpsum Price adalah suatu kontrak yang mana volume pekerjaan yang tercantum pada kontrak tidak boleh ditinjau ulang.

b. Unit Price (Harga Satuan):

Pada umumnya, kontrak Unit Price yaitu kontrak dimana volume pekerjaan yang terdapat pada kontrak hanya perkiraan dan akan ditinjau ulang untuk memastikan volume pekerjaan yang benar-benar dilaksanakan.

2. Aspek Perhitungan Jasa

a. Biaya Tanpa Jasa (Cost Without Fee)

b. Biaya Ditambah Jasa Pasti (Cost plus Fee)

3. Aspek Cara Pembayaran

a. Cara Pembayaran Bulanan (Monthly Payment)

b. Cara Pembayaran atas Prestasi (Stage Payment) 


\section{c. Pra Pendanaan Penuh dari Penyedia Jasa (Contractor's Full Prefinanced)}

4. Aspek Pembagian Tugas

a. Bentuk Kontrak konvensional

b. Bentuk Kontrak Spesialis

c. Bentuk Kontrak Rancang Bangun

d. Bentuk Kontrak Engineering, Procurement \& Construction (EPC)

e. Bentuk Kontrak BOT/BLT

f. Bentuk Swakelola

\subsection{Rencana Anggaran Biaya (RAB)}

Menurut Ervianto ${ }^{[1]}$ Rencana Anggaran Biaya (RAB) adalah perkiraan biaya yang akan digunakan pada pekerjaan proyek konstruksi yang disusun berdasarkan gambar atau bestek. RAB bukan biaya yang sebenarnya, tetapi biaya yang digunakan kontraktor untuk menentukan harga penawaran, sehingga dalam pelaksanaannya nanti tidak menghabiskan biaya yang lebih tinggi dari penawaran dan bias jadi biaya kurang dari penawaran yang ditetapkan.

Kegiatan estimasi dalam proyek konstruksi dilakukan dengan tujuan tertentu tergantung dari pihak yang membuatnya. Owner membuat estimasi dengan dibantu oleh konsultan, bertujuan untuk mendapatkan informasi tentang biaya yang harus disiapkan untuk merealisasikan proyeknya. Hasil estimasi ini disebut dengan Owner Estimate (OE).

Pihak kontraktor membuat estimasi bertujuan untuk melangsungkan penawaran terhadap proyek konstruksi. Kontraktor bisa memenangkan pelelangan apabila penawaran yang diajukan mendekati Owner Estimate (OE). Tahap yang dilakukan untuk menyusun $\mathrm{RAB}$ antara lain :

- Mengumpulkan data tentang jenis, harga serta kemampuan pasar dalam menyediakan bahan atau material konstruksi secara berkelanjutan.

- Mengumpulkan data tentang upah pekerja yang berlaku di daerah lokasi proyek atau upah yang biasanya jika pekerja didatangkan dari luar daerah ke lokasi proyek.

- Menganalisis perhitungan bahan dan upah dengan caara analisis yang diyakini benar dalam pembuatan anggaran. Dipasaran ada buku SNI analisa upah dan bahan.

Data yang diperlukan untuk penyusunan RAB sebagai berikut:

a. Peraturan dan syarat-syarat (RKS atau kontrak).

b. Gambar rencana.

c. Berita acara atau risalah penjelasan pekerjaan (untuk bangunan yang dilelang).

d. Buku analisa upah dan bahan (SNI analisa upah dan bahan). e. Daftar analisa harga upah dan bahan.

f. Peraturan-peraturan normalisasi yang bersangkutan.

g. Peraturan-peraturan bangunan negara dan bangunan setempat.

\subsection{Pelaksanaan Proyek}

Tahap Pelaksanaan di lapangan dimulai dari penetapan pemenang lelang dan diikuti dengan menerbitkan Surat Perintah Kerja serta penyerahan lapangan dengan segala kondisi kepada kontraktor. Kontraktor memulai kegiatan dengan mengeluarkan surat pemberitahuan saat mulai bekerja sekaligus memberi informasi struktur organisasi dan petugas lapangannya. Kemudian dilakukan pekerjaan persiapan, pengujian material, survei pengukuran dan prosedur penanganan administratif.

Selanjutnya dilakukan pengembangan jadwal rencana kerja menjadi jadwal yang lebih rinci. Pengembangan jadwal rencana kerja harus mampu mengantisipasi kemungkinan timbulnya permasalahan dan hambatan, termasuk solusinya. Jadwal rencana detail berlaku sebagai kerangka induk untuk dijabarkan lebih detail lagi dalam bentuk jadwal pengadaan tenaga kerja, material, dan alat-alat, jadwal penagihan, pembayaran prestasi dan penyusunan alur kas. Kemudian perlu ditetapkan pedoman praktis mekanisme dalam rangka mewujudkan sistem pengelolaan, koordinasi, pengendalian dan pemeriksaan pekerjaan kontraktor sampai sedetail mungkin.

Selama proses konstruksi berjalan dilakukan pengendalian dengan mengikuti laporan dan evaluasi pekerjaan, termasuk jadwal rencana kerja yang dipersiapkan secara teratur dalam waktu periodik harian, mingguan dan bulanan. Laporan dilengkapi foto-foto keadaan dan perkembangan di lapangan yang disertai juga catatan penting seperlunya. Penerapan pelaksanaan pekerjaan yang didasari pada rencana kerja dari waktu ke waktu harus selalu di awasi, termasuk mengevaluasi setiap kendala dan hambatan yang dihadapi agar dapat diberikan cara solusinya. Untuk itu perlu diadakan rapat koordinasi secara bertahap.

Setiap proses pelaksanaan konstruksi memerlukan program pengendalian mutu hasil pekerjaan sesuai pada sistem pengendalian yang menyeluruh. Pelaksanaan tugas kegiatan pengendalian mutu pada hakikatnya adalah pemantauan langkah demi langkah terhadap proses pelaksanaan pekerjaan. Jadi tidak hanya memberikan penilaian terhadap hasil akhir suatu proyek. Proses pemantauan mencakup penilaian terhadap metode kerja, ketrampilan kerja, pengadaan material, pengadaan peralatan, pengadaan tenaga kerja, termasuk keselamatan dan keamanan kerja.

\subsection{Pengendalian Biaya}


Menurut Asiyanto ${ }^{[4]}$ dalam suatu kegiatan proyek konstruksi harus selalu ada pengendalian biaya, waktu, dan kualitas agar kegiatan dalam proyek tersebut dapat berjalan lancar sesuai dengan rencana. Pengendalian biaya meliputi pengurangan biaya. Pengendalian biaya dipandang sebagai cara untuk mencapai target biaya dalam suatu kegiatan.

\subsubsection{Pengertian Pengendalian}

Menurut Soeharto[5] pengendalian/control adalah usaha yang sistematis dalam menentukan standar yang sesuai dengan sasaran perencanaan, merancang sistem informasi, membandingkan pelaksanaan standar, menganalisa kemungkinan adanya penyimpangan antara pelaksanaan dan standar, kemudian mengambil tindakan pembetulan yang diperlukan agar sumber daya digunakan secara efektif dan efisien dalam rangka mencapai sasaran.

Pengendalian bertujuan untuk memantau dan membimbing pelaksanaan pekerjaan agar sesuai dengan perencanaan. Ini berarti berbagai kegiatan dan aspek yang dikendalikan sama dengan yang direncanakan. Garis besar lingkup/obyek pengendalian proyek adalah sebagai berikut :

1. Organisasi dan personil

Memantau apakah organisasi pelaksana proyek dibentuk seperti rencana, apakah pengisian personil memenuhi kualifikasi, dan apakah jumlahnya telah terpenuhi.

2. Waktu atau jadwal

Dalam aspek ini objek pengendalian sangat ekstensif dan terjadi sepanjang siklus proyek. Dan proyek konstruksi obyek utamanya adalah kegiatan engineering, pengadaan, pabrikasi, dan konstruksi.

3. Anggaran biaya dan jam-orang

Seperti halnya aspek waktu (jadwal) maka pengendalian anggaran dan pemakaian jam-orang tejadi sepanjang siklus proyek, dengan potensi keberhasilan yang lumayan besar berada di awal proyek pada saat merumuskan definisi lingkup kerja.

4. Pengendalian pengadaan

Penekanan pengendalian pengadaan di samping aspek biaya, jadwal, dan mutu juga ada beberapa masalah prosedur dan peraturan yang diberlakukan.

5. Pengendalian lingkup kerja

Pengendalian lingkup kerja hampir sama pembahasan dan permasalahan dengan aspek biaya. Penting dilakukan pada tahap engineering, karena banyak sekali alternatif yang bisa dipilih.

6. Pengendalian mutu

Mencakup masalah yang cukup banyak, dengan tujuan utama produk proyek harus dalam keadaan fitness for use (sesuai untuk digunakan) di mulai dari menyusun program sampai dengan inspeksi dan uji coba operasi atau penggunaan.

7. Pengendalian kinerja
Mengawasi dan mengendalikan aspek biaya serta jadwal secara terpisah juga tidak memberikan penjelasan mengenai kinerja pada saat pelaporan. Seperti suatu pekerjaan berlangsung dengan cepat dari jadwal yang ditentukan, belum tentu hal tersebut merupakan kabar yang menggembirakan sebab ada kemungkinan biaya yang dikeluarkan per unitnya melebihi anggaran yang di tentukan. Dengan kata lain berarti pemakaian biaya tidak efisien dan dapat mengakibatkan proyek secara keseluruhan tidak dapat diselesaikan karena tidak cukupnya dana. Untuk mengkaji kemungkinan terjadinya hal-hal seperti itu diperlukan pengawasan dan pengendalian kinerja.

Suatu pengendalian proyek yang efektif ditandai dengan beberapa hal seperti berikut:

1. Tepat waktu dan peka terhadap penyimpangan yang terjadi.

2. Bentuk tindakan yang diadakan harus tepat dan benar, oleh karena itu diperlukan kemampuan dan kecakapan dalam menganalisis indikator secara akurat obyektif.

3. Penggunaan waktu serta tenaga yang efisien.

4. Komunikasi yang baik dari pelaksana proyek sehingga tindakan koreksi terhadap permasalahan dapat segera terlaksana.

5. Pengendalian biaya proyek.

6. Dapat memberikan petunjuk seperti perkiraan hasil pekerjaan yang akan datang.

\subsubsection{Pengertian Pengendalian Biaya}

Menurut Dipohusodo ${ }^{[2]}$ Rencana keuangan atau anggaran proyek merupakan salah satu hal yang harus di awasi dalam pengendalian proyek konstruksi, oleh karena itu dibutuhkan pengendalian biaya pada proyek konstruksi. Pengendalian biaya adalah suatu kegiatan proyek mengenai biaya yang akan dikeluarkan agar terhindar melebihi anggaran keuangan proyek.

Pengendalian biaya sebenarnya merupakan bagian dari manajemen biaya dan manajemen kontrol dari suatu kegiatan konstruksi. Hal - hal yang harus terdapat pada manajemen biaya yang baik untuk pengendalian biaya, antara lain adalah adanya estimasi biaya, laporan keuangan proyek, cash flow proyek, perhitungan biaya pengeluaran tambahan. Filosofi secara luas untuk pengendalian biaya adalah didasarkan atas tiga hal, yaitu :

1. Adanya dorongan dari kesadaran atas biaya pada setiap tahapan pelaksanaan konstruksi.

2. Adanya persyaratan data, tentang biaya yang akurat dan tepat waktu serta gambaran ke depan, dengan mengawasi keadaan atau trend dari biaya yang tidak diinginkan.

3. Adanya tindakan yang efektif serta cepat, untuk menghadapi persoalan dan memberikan umpan balik untuk langkah perbaikan selanjutnya.

Dalam kegiatan usaha jasa konstruksi, pengendalian biaya sangat penting adapun untuk menjaga kelangsungan hidup perusahaan dengan kata lain 
adalah kesuksesan perusahaan tersebut. Hal ini dipengaruhi oleh sifat usaha jasa konstruksi yang selalu menghadapi dilema, yaitu:

1. Harga jual (nilai kontrak) yang bersifat konservatif (relatif tetap untuk nilainya)

2. Biaya produksi (biaya pelaksanaan proyek), yang bersifat fluktuatif selama dalam proses pelaksanaan, dan cenderung membesar apabila tidak dikendalikan.

Untuk menghadapi kondisi yang dilematis tersebut, dibutuhkan dua kemampuan yang sangat mendasar agar perusahaan dapat terus sukses dan dapat berkembang, yaitu:

1. Kemampuan tentang biaya konstruksi (contruction cost), untuk memenangkan persaingan harga secara aman (cost estimate).

2. Kemampuan untuk melakukan pengendalian terhadap biaya (cost control).

Adapun akibat dari minimnya kedua kemampuan tersebut, dapat menyebabkan kerugian proyek, yang disebabkan oleh hal-hal sebagai berikut :

1. Penawaran yang terlalu rendah (Low bid), yaitu salah dalam cost estimating.

2. Informasi/pengetahuan yang minim tentang keadaan/kondisi pekerjaan.

3. Naiknya harga dari beberapa sumber daya yang digunakan di proyek selama konstruksi dilakukan, yang tidak diamankan dalam kontrak konstruksi (respon terhadap resiko).

4. Keadaan lapangan/cuaca yang buruk yang terjadi di luar harapan dan tidak dapat di kendalikan.

5. Pemilihan metode konstruksi yang kurang tepat atau sedikit keliru.

6. Manajemen dan Pengawasan yang kurang efektif.

Pengendalian biaya utama bertujuan penjaminan biaya akhir proyek agar tidak melapaui pelaksanaan rencana anggaran, selain itu dalam pengendalian biaya juga mengandung tujuan lainnya, yaitu:

1. Menekan biaya/pengeluaran serendah mungkin.

2. Dapat mendatangkan keuntungan dari pengerjaan proyek.

3. Agar perencanaan yang diinginkan sesuai kenyataan.

4. Memberikan informasi sehingga bila ada penyimpangan dapat segera dilakukan tindakan perbaikan semestinya.

\subsubsection{Penambahan Biaya}

Menurut Dipohusodo ${ }^{[2]}$ dengan kurangnya pengawasan dalam proyek konstruksi dapat menimbulkan berbagai macam kerugian dan permasalahan yang dapat menghambat pekerjaan proyek tersebut terlaksana antara lain, penambahan biaya, keterlambatan dalam penyelesaian proyek dan penyimpangan dari kualitas mutu akhir.

\subsubsection{Penambahan Biaya Proyek}

Journal of The Civil Engineering Student

Vol. 3. No. 2, Agustus 2021, Halaman 169-175
Menurut Martho $^{[6]}$ biaya proyek merupakan pengeluaran yang dibebankan pada proyek tetapi tidak dimasukkan pada upah kerja, biaya material, atau peralatan, seperti bangunan kantor, lapangan beserta perlengkapannya, biaya telepon kantor lapangan, kebutuhan akomodasi lapangan seperti listrik, air bersih, air minum, sanitasi, dan sebagainya.

Suatu proyek dapat dikatakan mengalami pembengkakan dana apabila pengeluaran biaya proyek melebihi dari anggaran biaya proyek yang direncanakan sesuai dengan nilai kontrak (Soeharto, 1997). Penambahan dana dapat terjadi akibat dari kesalahan yang terjadi pada setiap aspek dari tahapan proses konstruksi.

\subsection{Faktor-Faktor Penyebab Penambahan Biaya Proyek}

Menurut Darmawan ${ }^{[7]}$ Pada penelitian sebelumnya dijabarkan mengenai beberapa permasalahan yang bisa terjadi pada penyelanggaraan proyek konstruksi, beberapa faktor penyebab terjadinya penambahan biaya pelaksanaan pada proyek konstruksi, yaitu perencanaan, estimasi biaya, aspek keuangan proyek, material, tenaga kerja, waktu pelaksanaan, peralatan, dan hubungan kerja.

\subsection{Kualifikasi Jasa Pelaksana Konstruksi}

Golongan kualifikasi usaha jasa perencana konstruksi dan usaha jasa pengawas konstruksi didasarkan pada kriteria tingkat atau kedalaman kompetensi dan potensi kemampuan usaha, serta kemampuan melakukan perencanaan dan pengawasan pekerjaan berdasarkan kriteria resiko, kriteria penggunaan teknologi, kriteri besaran biaya (nilai proyek atau nilai pekerjaan).

\section{Metodologi Penelitian}

Metode dalam penelitian ini adalah penelitian kuantitatif dimana suatu proses penemuan pengetahuan yang menggunakan data berupa angka sebagai alat menganalisis keterangan mengenai apa yang ingin diketahui. Jenis penelitian yang digunakan adalah penelitian survey.

\subsection{Lokasi Objek dan Subjek Penelitian}

Perencanaan biaya dalam pembangunan proyek konstruksi gedung BPJN di Kota Banda Aceh dijadikan sebagai subjek dalam penelitian ini. Objek penelitian ini yaitu perusahaan konstruksi yang beralamat di Kota Banda Aceh.

\subsection{Pengumpulan Data}

Teknik pengumpulan data yang digunakan dalam penelitian ini adalah teknik survey. Pengumpulan data dilakukan dengan mensurvey langsung proyek konstruksi gedung BPJN di Kota 
Banda Aceh. Data yang diperlukan berupa RAB dan Time Schedule.
a. Data Primer
Data yang hasilnya diproses serta digunakan langsung untuk meraih tujuan dari penelitian.

b. Data Sekunder

Data penunjang yang digunakan untuk mendapatkan data primer. Data sekunder pada penelitian ini diperoleh dari beberapa responden. Jenis data yang dikumpulkan adalah data harga dan volume diperoleh dari dokumen RAB.

\subsection{Tahapan Pelitian} berikut :

Adapun tahapan penelitian adalah sebagai

1. Kajian literatur

Pengumpulan data yang dilakukan dengan membaca jurnal-jurnal, buku-buku literature, majalah, internet dan penelitian terdahulu yang berkaitan dengan penelitian ini.

2. Perumusan masalah

Mengetahui masalah apa saja yang terdapat di lingkup penelitian, maka peneliti merumuskan beberapa masalah yang ingin diketahui serta dilusuri.

3. Batasan masalah

Melakukan observasi, identifikasi masalah, dan perumusan masalah, maka peneliti dapat membuat batasan penelitian yang digunakan untuk membatasi penelitian ini.

4. Pengambilan data

Meminta langsung beberapa dokumen pada proyek konstruksi gedung BPJN Banda Aceh seperti RAB dan lain-lain.

5. Pengolahan data

Pengolahan data dalam penelitian ini akan menggunakan Microsoft Excel.

\section{Hasil dan Pembahasan}

\subsection{Deskripsi Umum Proyek}

Berikut ini adalah beberapa data dari proyek yang akan diteliti, berupa data umum proyek, daftar pekerjaan, data teknis proyek, durasi dan biaya setiap item pekerjaan.

\subsubsection{Data Umum Proyek}

Data proyek Pembangunan Gedung BPJN Banda Aceh adalah sebagai berikut :

Nama Proyek : Pembangunan Gedung BPJN Aceh

Lokasi : Banda Aceh

Nomor Kontrak : HK.02.03/Bb1PRESV/92/ APBN/2018

Tanggal Kontrak : 08 Juni 2018

Nilai kontrak : Rp. 20.399.655.955,40

Sumber dana : APBN

Tahun anggaran : 2017
Instansi

Kontraktor

: Kementerian Pekerjaan Umum dan Perumahan Rakyat

: CV. Aceh Lhee Dimensi

\subsection{Harga Satuan Pekerjaan}

Harga satuan pekerjaan adalah jumlah harga bahan dan upah tenaga kerja berdasarkaan dari perhitungan analisis yang berisi beberapa daftar pekerjaan, volume pekerjaan, satuan dari jenis atau macam pekerjaan. Sedangkan harga bahan didapat langsung dari pasaran. Dikumpulkan dalam satu daftar yang disebut daftar satuan bahan.

\subsubsection{Perhitungan Koefisien Bahan}

1) Pekerjaan beton Sloof

Dari data, untuk pekerjaan beton sloof dengan volume dengan kebutuhan material adalah sebagai berikut:

$\begin{aligned} \text { Kebutuhan semen } & =\text { volume } \times \text { koefisien bahan } \\ & =0.32 \mathrm{~m}^{3} \times 371 \mathrm{~kg} \\ & =118.72 \\ \text { Kebutuhan pasir } & =\text { volume } \times \text { koefisien bahan } \\ & =0.32 \mathrm{~m}^{3} \times 698 \mathrm{~kg} \\ & =223.36 \\ \text { Kebutuhan kerikil = volume } \times \text { koefisien bahan } & =0.32 \mathrm{~m}^{3} \times 1047 \mathrm{~kg} \\ & =335.04 \\ \text { Kebutuhan air } & =\text { volume } \times \text { koefisien bahan } \\ & =0.32 \mathrm{~m}^{3} \times 215 \text { liter } \\ & =68.8\end{aligned}$

2) Pekerjaan bekisting sloof

Dari data, untuk pekerjaan bekisting sloof dengan volume dengan kebutuhan material adalah sebagai berikut:

Kebutuhan kayu kelas III = volume $\mathrm{x}$ koefisien bahan

$$
=2.12 \mathrm{~m}^{2} \times 0,043 \mathrm{~m}^{3}
$$

$$
=0.0912
$$

Kebutuhan paku kayu $=$ volume $\mathrm{x}$ koefisien bahan

$$
=2.12 \mathrm{~m}^{2} \times 0,3 \mathrm{~kg}
$$$$
=0.636
$$

Kebutuhan pelumas/oli = volume $\mathrm{x}$ koefisien bahan

$$
=2.12 \mathrm{~m}^{2} \times 0,1 \text { liter }
$$

$$
=0.212
$$

3) Pekerjaan pembesian sloof

Dari data, untuk pekerjaan pembesian sloof dengan volume dengan kebutuhan material adalah sebagai berikut:

Kebutuhan besi beton ulir $=$ volume $\mathrm{x}$ koefisien bahan

$$
\begin{aligned}
& =18.86 \mathrm{~kg} \times 10,5 \mathrm{~kg} \\
& =198.03
\end{aligned}
$$

Kebutuhan kawat beton = volume $\mathrm{x}$ koefisien bahan

$$
=18.86 \mathrm{~kg} \times 0,15 \mathrm{~kg}
$$$$
=2.829
$$ 


\subsubsection{Harga Satuan Pekerjaan Sloof}

Berikut harga satuan pokok pekerjaan sloof yang terdiri dari pengecoran, pembesian dan bekisting, sesuai dengan (Analisa Harga Satuan Pekerjaan) AHSP 2016.

\section{Tabel 1. Harga Satuan Pekerjaan Beton Sloof}

\begin{tabular}{|c|c|c|c|c|c|c|}
\hline \multicolumn{7}{|c|}{ ANALISA HARGA SATUAN PEKERJAAN } \\
\hline \multirow{2}{*}{\multicolumn{2}{|c|}{ Jenis Pekerjaan }} & & & & & \\
\hline & & Beton Mutu F'c = 19, & 1pa (K 22: & & & \\
\hline \multirow{2}{*}{\multicolumn{2}{|c|}{$\begin{array}{l}\text { Satuan / Unit } \\
\text { Analisa }\end{array}$}} & M3 & & & & \\
\hline & & AHSP PU A.4.1.1.7 & & & & \\
\hline \multirow{2}{*}{$\frac{\text { No }}{\text { A. }}$} & \multicolumn{2}{|r|}{ Uraian } & Satuan & Koefisien & Harga Satuan & Jumlah Harga \\
\hline & \multicolumn{2}{|l|}{ TENAGA } & & & & \\
\hline 1 & \multicolumn{2}{|l|}{ Pekerja } & $\mathrm{OH}$ & 1,6500 & $85.000,00$ & $140.250,00$ \\
\hline 2 & \multicolumn{2}{|l|}{ Tukang } & $\mathrm{OH}$ & 0,2750 & $95.000,00$ & $26.125,00$ \\
\hline 3 & \multicolumn{2}{|l|}{ Kepala Tukang } & $\mathrm{OH}$ & 0,0280 & $120.000,00$ & $3.360,00$ \\
\hline \multirow[t]{2}{*}{4} & Mandor & & $\mathrm{OH}$ & 0,0830 & $110.000,00$ & $9.130,00$ \\
\hline & & & & \multicolumn{2}{|c|}{ Jumlah Tenaga Kerja } & $178.865,00$ \\
\hline B. & BAHAN & & & & & \\
\hline 1 & \multicolumn{2}{|c|}{ Semen PC@40 zak } & $\mathrm{kg}$ & 371,00 & $1.617,20$ & $599.981,20$ \\
\hline 2 & \multicolumn{2}{|c|}{ Pasir Beton } & $\mathrm{kg}$ & 698,00 & 155,50 & $108.539,00$ \\
\hline 3 & Kerikil & & $\mathrm{Kg}$ & $1.047,00$ & 129,01 & $135.070,76$ \\
\hline \multirow[t]{2}{*}{4} & Air & & Liter & 215,00 & 250,00 & $53.750,00$ \\
\hline & & & & & \multirow{2}{*}{ Jumlah Bahan } & $897.340,96$ \\
\hline \multirow[t]{2}{*}{ c. } & \multirow{2}{*}{\multicolumn{2}{|c|}{ PERALATAN }} & & & & \\
\hline & & & & \multicolumn{2}{|c|}{ Jumlah Peralatan } & \\
\hline D & \multicolumn{5}{|c|}{ Jumlah Harga Tenga Kerja, Bahan dan Peralatan $(\mathrm{A}+\mathrm{B}+\mathrm{C})$} & $1.076 .205,96$ \\
\hline$E$ & \multirow{2}{*}{\multicolumn{2}{|c|}{ Overhead \& Profit }} & $10 \%$ & $\mathrm{X} \quad \mathrm{D}$ & & $107.620,60$ \\
\hline$F$ & & & & & & $1.183 .826,55$ \\
\hline
\end{tabular}

Tabel 2. Harga Satuan Pekerjaan Bekisting Sloof

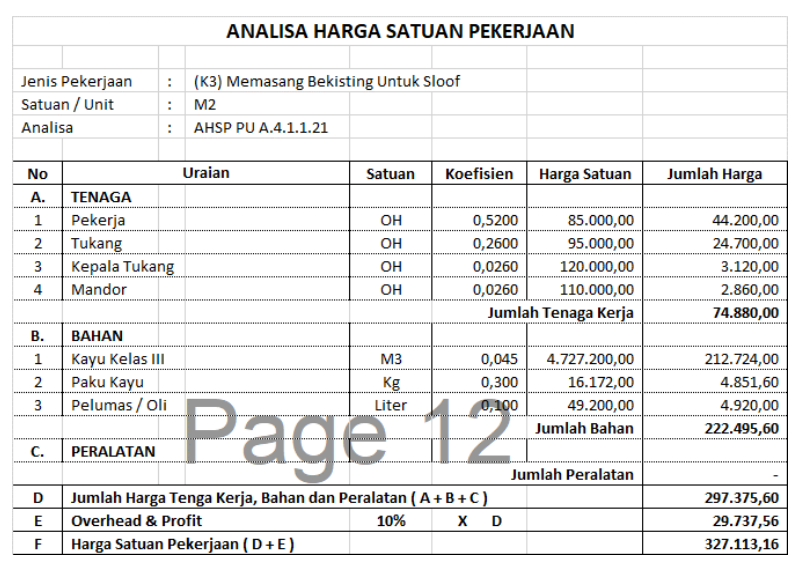

Tabel 3. Harga Satuan Pekerjaan Pembesian Sloof

\begin{tabular}{|c|c|c|c|c|c|c|}
\hline \multicolumn{7}{|c|}{ ANALISA HARGA SATUAN PEKERJAAN } \\
\hline \multicolumn{2}{|c|}{ Jenis Pekerjaan } & \multicolumn{3}{|c|}{ Pembesian $10 \mathrm{Kg}$ Dengan Besi Ulir } & & \\
\hline \multirow{2}{*}{\multicolumn{2}{|c|}{$\begin{array}{l}\text { Satuan / Unit } \\
\text { Analisa }\end{array}$}} & $\mathrm{Kg}$ & & & & \\
\hline & & AHSP PU A.4.1.1.17 & & & & \\
\hline No & \multicolumn{2}{|r|}{ Uraian } & Satuan & Koefisien & Harga Satuan & Jumlah Harga \\
\hline A. & TENAGA & & & & & \\
\hline 1 & Pekerja & & $\mathrm{OH}$ & 0,0700 & $85.000,00$ & $5.950,00$ \\
\hline 2 & Tukang & & $\mathrm{OH}$ & 0,0700 & $95.000,00$ & $6.650,00$ \\
\hline 3 & Kepala Tukang & & $\mathrm{OH}$ & 0,0070 & $120.000,00$ & 840,00 \\
\hline \multirow[t]{2}{*}{4} & Mandor & & $\mathrm{OH}$ & 0,0040 & $110.000,00$ & 440,00 \\
\hline & & & & \multicolumn{2}{|c|}{ Jumlah Tenaga Kerja } & $13.880,00$ \\
\hline B. & BAHAN & & & & & \\
\hline 1 & Besi Beton Ulir & & $\mathrm{kg}$ & 10,500 & $14.000,00$ & $147.000,00$ \\
\hline \multirow[t]{2}{*}{2} & Kawat Beton & & $\mathrm{kg}$ & 0,150 & $16.172,00$ & $2.425,80$ \\
\hline & & & & & Jumlah Bahan & $149.425,80$ \\
\hline \multirow[t]{2}{*}{ c. } & PERALATAN & & & & & \\
\hline & & & & \multicolumn{2}{|c|}{ Jumlah Peralatan } & \\
\hline D & \multicolumn{4}{|c|}{ Jumlah Harga Tenga Kerja, Bahan dan Peralatan $(A+B+C)$} & & $163.305,8 \mathrm{C}$ \\
\hline$E$ & & Per Kg P & nbesian $=$ & $\mathrm{D} / \mathbf{1 0}$ & & $16.330,58$ \\
\hline $\mathrm{F}$ & Overhead \& Prc & & $10 \%$ & $x \quad E$ & & $1.633,0 \mathrm{C}$ \\
\hline G & Harga Satuan $P$ & ekerjaan $(E+F)$ & & & & $17.963,64$ \\
\hline
\end{tabular}

\section{Kesimpulan dan Saran}

Adapun hasil pengolahan data dan pembahasan, maka diperoleh beberapa kesimpulan sebagai hasil dari penelitian ini. Saran dikemukakan dengan tujuan agar penelitian ini dapat dikembangkan dan dilanjutkan oleh penelitian lain.

\subsection{Kesimpulan}

Berdasarkan hasil penelitian mengenai perencanaan harga material pembangunan proyek BPJN Banda Aceh dapat di simpulkan sebagai berikut:

1. Koefisien bahan atau material pekerjaan sloof (AHSP 2016)

2. Harga bahan pekerjaan pengecoran, pembesian dan bekisting dari AHSP 2016

\subsection{Saran}

Penelitian ini diharapkan dapat dilanjutkan oleh peneliti-peneliti lain, oleh karena itu peneliti memberikan saran agar harga material bahan bangunan pekerjaan disesuaikan dengan daerah pembangunan proyek tersebut.

\section{Daftar Pustaka}

[1] Ervianto, Wulfram I., 2005. Manajemen Proyek Konstruksi. Yogyakarta.

[2] Dipohusodo, 1996. "Manajemen Proyek dan Konstruksi” Jilid I, Penerbit Kanisius, Yogyakarta.

[3] Faizal. 2016. "Optimasi Pendanaan Proyek Pembangunan Gedung Velodrome Dengan Teknik Pemograman Linier". Universitas Negeri Semarang. Jurnal Teknik Sipil dan Perencanaan, No. 1, Vol. 18, halaman 1-8.

[4] Asiyanto, 2003. Pendapatan Kontrak Konstruksi. Jakarta: Salemba Empat.

[5] Soeharto, Iman, (1997), Manajemen Proyek, Erlangga, Jakarta.

[6] Martho. F. T., Rantung. J. P., Langi. J. E. Ch., dan Sibi. M. 2012. "Analisis Cash Flow Optimal Pada Kontraktor Proyek Pembangunan Perumahan”. Jurnal Sipil Statik, Vol. 1 No. 1, halaman 60-64.

[7] Darmawan. H, (2004),Dasar Perancangan Teknik, Bandung: Institut Teknologi Bandung. 